\title{
LOS COMPLEMENTOS DE LOS VERBOS PSICOLÓGICOS EN ESPAÑOL Y LA PERSPECTIVA NO DISCRETA DE LA CATEGORIZACIÓN
}

\author{
$M^{a}$ ANTONIA MARTÍNEZ LINARES \\ (Universidad de Alicante)
}

\begin{abstract}
RESUMEN
In this paper I have tried to present the concept of prototype, which has been incorporated in Functionalism and Cognitive Linguistics, as a useful descriptive tool to characterize grammatical functions. In order to do that, I have analyzed direct and indirect objects in sentences with psych-verbs, like gustar, encantar, enfurecer.
\end{abstract}

\section{Introducción}

Los predicados con verbos psicológicos o de afección psíquica que implican un 'experimentador' 'humano' o 'animado' como complemento ${ }^{2}$ - enfurecer,

1 Entendiendo por 'experimentador' el papel semántico correspondiente a la entidad 'humana' o 'animada' que 'experimenta' o 'resulta afectada por' un proceso psicológico.

2 Los verbos del tipo temer, amar, detestar, odiar, también considerados psicológicos o de afección psíquica, parecen proyectar los mismos papeles semánticos, pero su realización sintáctica es distinta. El 'experimentador' se presenta como sujeto de la construcción, no como complemento: $\mathrm{El}$ abuelo detesta las Navidales, María ama la soledad; pero Al abuelo le desagradan las Navidades, A Maria le gusta la soledad. La aparente inversión de papeles fue uno de los motivos por los que, en estudios de orientación generativista, ambos tipos de estructuras se relacionaron derivacionalmente. Pero hoy parece asumido, incluso en trabajos de tipo generativo (cf. Belletti y Rizzi, 1987; Gràcia i Solé, 1989), que los dos tipos de verbos psicológicos constituyen clases léxicas distintas que proyectan también cstructuras diferentes. En cualquier caso, las predicaciones con verbos psicológicos del tipo amar, temer, etc., parecen mucho menos problemáticas que las construidas con verbos como preocupar; enfurecer, etc.; tal vez porque, aunque ni temer, amar, odiar son verbos de acción, ni su sujeto es 'agente' ni el objeto resulta afectado por el proceso, su estructuración presenta más analogías con las construcciones transitivas prototípicas, las que tienen un agente humano como sujeto y un paciente como objeto. 
atemorizar, preocupar, aburrir, divertir, gustar, repugnar, desgradar, etc.revisten un cierto interés para la gramática, ya que, por un lado, llevan aparejada una serie de problemas ya clásicos en los estudios gramaticales del español: la presencia de $a$ ante complemento u objeto ${ }^{3}$ directo, el fenómeno del leísmo, el alcance de la pasivización en las construcciones transitivas, además de la fluctuación entre complemento directo y complemento indirecto que singulariza a un número considerable de estos verbos. Por otro lado, tal como ha puesto de relieve Vázquez Rozas (1995) en su excelente análisis de las cláusulas biactanciales, las peculiaridades de estos predicados plantean también interrogantes de alcance más amplio, en la medida en que pueden tener por objeto cuestiones fundamentales en el ámbito gramatical o sintáctico ${ }^{4}$. Entre ellas, la adecuación de una concepción «formalista» y «discreta» de las funciones sintácticas centrales -el complemento directo y el indirecto entre ellas-, habida cuenta de lá relación existente entre los rasgos morfosintácticos asociados a una función -clítico, pasivización, presencia o ausencia de preposición- y la multiplicidad de factores semánticos e informativos que configuran la transitividad como una propiedad gradual, en la que está implicada la predicación en su totalidad.

A' ello habría que añadir que cuando, como sucede con este tipo de predicados, se hace preciso hablar de las fluctuaciones entre complemento directo y complemento indirecto, o de las semejanzas existentes entre ambos tipos de complementos; de casos cuya asignación a una u otra categoría funcional puede resultar problemática o de los criterios utilizados para diferenciarlas, deberíamos -en el supuesto ideal- tener como referencia un concepto claro de complemento directo, de complemento indirecto $y$, por supuesto, de función sintáctica.

Pero sería ocioso pretender presentar, como punto de partida o como punto de llegada, una aproximación clara, productiva y exenta de vaguedad a estos conceptos, o incluso a las nociones que realmente pueden estar implicadas en el uso de estos términos en las descripciones sintácticas, puesto que las funciones han sido, y continúan siendo, un problema para la teoría sintáctica. Las siguientes palabras de Langacker (1987: 2) —referidas a conceptos tan básicos como 'nombre' o 'sujeto' - parecen perfectamente adecuadas a la forma en que comúnmente se hace uso de téminos como 'sujeto' o 'complemento directo'

Every linguist relies on these concepts, but few if any are prepared to define them in an adequate, explicit and revealing way. In explaining such

Dado el uso que se hace de los términos «complemento» u «objeto» en los estudios gramaticales del español, parece claro que «complemento directo» y «objeto directo», «complemento indirecto» $\mathrm{y}$ «objeto indirecto» pueden considerarse términos equivalentes.

Adcmás, claro está, de los problemas que el análisis de estos predicados pueda plantear en un marco teórico determinado, como la Teoría de la Rección y el Ligamiento, pongamos por caso (cf. Belletti y Rizzi, 1987). 
terms to students, we normally provide some examples, list some typical properties, and perhaps, offer a crude verbal definition that we know to be insatisfactory.

También la siguiente afirmación de Willems y Melis (1997: 5) resulta ilustrativa acerca de la imprecisión que aún rodea a las funciones; en este caso, se reliere en concreto al complemento directo:

En réalité l'objet occupe une position paradoxale dans la description linguistique: pivot incountournable de l'analyse en tant que partenaire privilégić du predicat élémentaire, il reste néanmoins largement insaisissable pour cause d'imprécision et d'ambigüité inhérents.

No parece, además, que la diversidad de las teorías desde las que se abordan en la actualidad los fenómenos sintácticos haya contribuido especialmente a clarificar el estatus de las funciones, aunque sí haya redundado en el extraordinario avance de las investigaciones sintácticas. Baste recordar que, como advertían Brown y Miller (1996), las teorías no sólo difieren en la consideración de las funciones como elementos primitivos o como derivados de una configuración estructural básica, sino también en la forma en que conciben la relación entre sintaxis, semántica y pragmática; de manera que, según señalaba Langacker (1991: 304-305), incluso los que aceptan estas categorías, «do not agree on whether they should be characterized in terms of meaning, grammar, discourse function or some combination thereof ${ }^{5}$. Sería difícil, pues, encontrar una base común en las aproximaciones, desde distintos marcos teóricos, al concepto de complemento directo, de complemento indirecto o, en general, de función sintáctica.

Deberemos prescindir, por tanto, de plantear un concepto claro, de uso generalizado, para cada uno de estos términos, y nos limitaresmos al uso, aparentemente no problemático que se hace de ellos en las descripciones gramaticales. No obstante, sí queremos considerar, aunque sea mínimamente, dos formas diferentes de abordar la caracterización de las funciones sintácticas: esa óptica discreta y formal, «minimalista en espíritu» (cf. Langacker, 1987: 17), inherente al funcionalismo de corte estructuralista que tan amplia difusión ha tenido en la lingüística hispana; una perspectiva no discreta, de base semántica, no minimalista —en cuanto que da cabida a una serie de propiedades más amplia- vinculada al «funcionalismo»o, en términos de Dik (1997: 4), al «paradigma luncional» de la gramática.

Según alirmaba Rojo (1979: 17), el hecho de abordar las funciones sintácticas supone, en cicrto modo, tratar «del problema de la situación de los fenómenos sintácticos con respecto a la generaljdad de los hechos linguísticos, de su carácter específico y, como consecuencia, de las relacioncs cxistentes entre la sintaxis y el resto de las disciplinas que se ocupan del lenguaje y de las Ienguass?. 
Veamos —o, más bien, recordemos- algunas de las peculiaridades de los predicados con verbos psicológicos que seleccionan un 'experimentador' 'humano' y 'animado' como complemento, y veamos, asimismo, a cuál de las dos perspectivas parecen adecuarse mejor los hechos.

\section{Los predicados psicológicos con complemento 'humano'}

En primer lugar, los verbos psicológicos que estamos considerando parecen proyectar una estructura semántica similar: además de implicar un 'experimentador' como complemento, también pueden presentar todos ellos un argumento 'causa' o, para algunos, 'tema', de carácter 'animado' o 'inanimado' como sujeto: Las palabras del director (CAUSA) enfurecieron a los empleados (EXP); el recuerdo de las pasadas heladas (CAUSA) atemorizaba a los agricultores (EXP); a Federico (EXP) le gusta la buena vida (CAUSA); a Maribel (EXP) le repugna esa risita (CAUSA).

No obstante, atendiendo a la realización sintáctica $(\mathrm{CD}, \mathrm{CI})$ del argumento 'experimentador', así como a las posibilidades de interpretación del papel semántico correspondiente al sujeto, se pueden diferenciar dos clases en el conjunto de estos verbos: en una de ellas quedarían englobados enfurecer, preocupar, aburrir, atemorizar y, lógicamente, todos aquellos que coincidan con ellos en su comportamiento (tranquilizar, emocionar, irritar, asustar, etc.); a la otra clase, menos extensa al parecer, pertenecerían, entre otros, gustar, repugnar, desagradar, encantar o apetecer?

Por lo que concierne a los verbos constitutivos de la primera clase, es de destacar, en primer lugar, que, según señalara Cano Aguilar (1981: 65), si su sujeto es 'humano' o 'animado' puede ser interpretado no sólo como 'causa', sino también como 'agente', como entidad que actúa de un modo deliberado y voluntario ${ }^{\sharp}$. Así, según sus palabras, en «Juan no logró alegrarme el sujeto puede

6 Para Belletti y Rizzi (1987), por ejemplo, el sujeto - sujeto superticial, de conformidad con su plantcamiento- conlleva el papel semántico 'tema', según el sentido que suele tener el término en los estudios generativistas. Un sentido un tanto ambiguo, pues si bien se define como «la entidad afectada por la acción expresada por el predicado, o la entidad que se mueve (con verbos de movimiento) o la entidad cuya locación se define (con un verbo que indica locación)» (Fernández Lagunilla y Anula Rebollo, 1995: 93), no siempre el uso del término corresponde claramente a este concepto. De ahí que parezca un papel semántico bastante neutro.

Para Cano Agtilar (1981: 66) o de Miguel (1992: 49), el sujeto de verbos como atemorizar, enfirecer, etc., puede interpretarse como una 'causa': una entidad, animada o inanimada, que, de manera no voluntaria, no controlada, desencadena el proceso psicológico designado por el verbo. En lo que sigue utilizaré preferentemente este término para referirme al papel semántico — uno de ellos al menos- del sujeto.

Al menos, cn una de las acepciones que tienen actualmente estos verbos.

También, por ejemplo, Belletti y Rizzi (1987: 68), en su análisis de los verbos psicológicos, señalan esa posibilidad: «un sujeto humano se puede interpretar como el que induce en el experimentante el proceso o estado psicológico en cuestión» y, por tanto, como agente. No obstante, de conformidad con sus planteamientos, cuando el sujeto es agente si es un sujeto profundo. Por 
ser 'agente' según su grado de voluntariedad en el proceso, o bien mera 'causa' desencadenante», y lo mismo puede hacerse extensivo a estos otros ejemplos: Antonio la atemorizó con sus palabras; el casero la asustó (para que se marcharaly.

Por lo que respecta a la función sintáctica o gramatical del sintagma alusivo al 'experimentador', es evidente que, en determinadas construcciones al menos, presenta el rasgo más comúnmente ${ }^{(1)}$ utilizado como criterio para identificar -no para definir ${ }^{11}$ - el complemento directo: la posibilidad de ser sustituido por un clítico de acusativo: Juan la atemorizó; el casero la asustó; su discurso los enfureció; la música los emocionó. Por ello, estos verbos se clasifican básicamente como transitivos, como verbos que pueden llevar un complemento directo.

Pero parece claro que ios complementos directos de los verbos psicológicos son, en buena medida atípicos, puesto que, al menos, no presentan los otros dos rasgos que, junto con la marca de acusativo, se han utilizado en las gramáticas del español para caracterizar o para identificar el complemento directo.

En primer lugar, no son, evidentemente, sintagmas nominales que se unen «al verbo sin necesidad de ningún índice explícito de función» (Alarcos, 1994: 176); son, por cl contrario, complementos directos 'preposicionales' ${ }^{\prime 2}$, precedidos de la preposición $a$, pues, al ser su papel semántico el de 'experimentador', habrán de presentar normalmente esos dos rasgos recogidos en la mayoría - si no en la totalidad- de las hipótesis planteadas para explicar el uso, ante complemento directo, de la preposición $a$ : es típicamente un complemento 'humano' y 'determinado', alto, en definitiva, en la jerarquía de animación y alto también en la jerarquía de determinación.

En segundo lugar, las construcciones con verbos psicológicos que implican un sujcto 'causa' en construcción transitiva, pueden dar lugar a construcciones pronominales medias o ergativas: El abuelo se enocionó con/por la visita; Federico se preocupó por la salud de María; la familia se intranquilizó con la

Lanto, Los precios de las casas lo asustan y ella lo asusta deliberadanente siempre que puede lendrían, a su juicio, una estructura-P diferente.

? La inclusión de la complementación final conllevaría, lógicamente, una interpretación agentiva.

10) La integración en el predicado mediante el clítico de acusativo, en caso de supresión o de tematización del complemento, ha sido a veces, de hecho, el único criterio empleado para la identificación del complemento directo; pero dejando al margen el fenómeno del leísmo que, según señalan Hernanz y Brucart (1987: 254), «entorpece la viabilidad de la pronominalización como prucbar de carácter funcional», lo cierto es que tampoco todos los complementos directos tienen, en cuanto a la pronominalización, cl mismo comportamiento: Piso no (*/o) tengo; gente desesperada he visto en todas partes.

II Como bien advicrte Rojo (1994: 20) al respecto, «los procedimientos empleados para marcar las lunciones pueden servir para identificar, pero no para definir»; la función sintáctica, según sus propias palabras «es algo mucho más profundo y difícil de asir» (ibid.).

12 Véase Pensado (cd.), El complemento directo preposicional, Madrid, Visor, 1995. 
noticia. Pero, frente a otras estructuras transitivas, no se pasivizan. Difícilmente, pues, el complemento podría convertirse en sujeto de una construcción pasiva: $*$ El abuelo fue emocionado por la visita; *Federico fue preocupado por la salud de Maria; *la familia fue intranquilizada por la noticia.

Un último aspecto que no puede pasarse por alto en estos complementos, por lo que concierne a las notas caracterizadoras del complemento directo, es que, si bien aceptan, como se ha dicho, la sustitución por el clítico de acusativo, el hecho de que el 'experimentador' — su papel semántico- sea típicamente 'humano' o, cuando menos, 'animado', hace que el fenómeno del leísmo tenga una especial repercusión en ellos ${ }^{13}$. Es bastante significativo al respecto que Gómez Torrego, en su Manual de español correcto (1993: 69 y sigs.) incluya estos verbos - a los que se refiere como verbos que significan «daño» o «agrado»y «provecho»entre aquellos que, incluso en zonas no leístas, provocan vacilación «a la hora de elegir la forma pronominal adecuada de c. directo o c. indirecto» (Gómez Torrego, 1993: 78). Así, por ejemplo, en el enunciado María preocupa a Juan constantemente, el complemento podría pronominalizarse mediante el clítico de acusativo (lo preocupa) o de dativo (le preocupa).

Pero, ciertamente, con esta clase de verbos psicológicos la incidencia del lé́smo viene a solaparse con otro aspecto que, como ya se ha mencionado, también singulariza a estos verbos: pueden oscilar entre el complemento directo y el indirecto $\sin$ que, en apariencia, varie la acepción del verbo ${ }^{14}$. Esto es, ateniéndonos a las marcas de identificación de los complementos, pueden oscilar entre el clítico de acusativo y el clítico de dativo, aun cuando se trate de un 'experimentador' 'humano' 'femenino': A María la asustó premeditadamente Juan para que le dejara el sitio; a María le asusta la soledad; su marido la tranquilizó como pudo; a Delia le tranquiliza el hecho de que hayas venido.

El clítico -y, por tanto, el tipo de complemento- parece fluctuar a veces sin motivación aparente. De hecho, podría decirse que una construcción como María preocupa a Juan constantemente no presenta indicios claros que permitan incluir el complemento en la categoría de los directos o de los indirectos. Pero, según ha puesto de relieve Vázquez Rozas (1995), la vacilación del clítico no es enteramente arbitraria; está relacionada con factores variables vinculados, no al complemento, sino a otros componentes de la cláusula: el contenido aspectual y la animación del sujeto, junto con el mayor o menor grado de voluntariedad y control que ejerza sobre el proceso, así como también, al parecer, con la tematización o no tematización del complemento. Así en El casero la asustó para

1.3 Naturalmente, cuando el complemento es, además de 'humano', 'masculino' se ajusta al supuesto cn el que, incluso desde un punto de vista normativo, se considera aceptable el leísmo.

14 Por supuesto, también son frecuentes los casos en que la construcción con $\mathrm{CI}$ o con $\mathrm{CD}$ diferencia accpciones de un mismo elemento léxico: La sorprendió llevándose las toallas; le sorprendió que se llevara las toallas; la malvada brija la encantó con una pócima; la bruja malvada es un personaje que le encanta (véase Vázquez Rozas, 1995: 175 y sigs.). 
que se marchara; a María le asusta la soledad; su marido la tranquilizó como pudo; a Delia le tranquiliza que hayas venido, la variación CD - CI puede hallarse en correlación con el hecho de que el sujeto se interprete como agente (el casero, su marido) y, por tanto, como entidad animada que actúa de manera deliberada y voluntaria, o como causa (la soledad, que hayas venido); con la tematización del complemento (en A María le asusta la soledad; a Delia le tranquiliza que hayas venido es el complemento, y no el sujeto, el elemento que ocupa la posición de tema); así como con el aspecto más o menos estativo (le asusta, le tranquiliza) o perfectivo (la asustó, la tranquilizó) de la cláusula. Es evidente, por lo demás, que todos estos aspectos pueden variar independientemente; no es extraño, pues, que se den vacilaciones en el clítico: el paso de un esquema transitivo a uno intransitivo puede ser, como frecuentemente se ha señalado, una cuestión de grado.

Los predicados psicológicos pertenecientes al segundo de los grupos que hemos dificrenciado - gustar, repugnar, apetecer ${ }^{15}$, encantar ${ }^{16}$, desagradar ${ }^{17}$ - se distinguen de los anteriores, por un lado, en que no admiten una interpretación agentiva del sujeto, ni aun en el caso de que este posea el rasgo 'humano' o 'animado' (A Eva le gusta mucho Brad Pitt; no sabes cuánto le desagrada ese muchacho). Por otro lado, estos verbos se clasifican básicamente como intransitivos, debido a que sólo admiten el clítico de dativo en caso de tematización o de supresión del complemento.

Debe destacarse, no obstante, que los complementos indirectos de los verbos psicológicos - y esto, naturalmente, se hace extensivo a los que acompañan a los predicados del primer tipo-, son también en buena medida problemáticos o atípicos ${ }^{18}$. No presuponen un complemento directo, sino que constituyen el único

15. Me reficro a la acepción correspondiente a la estructura que estamos considerando: aquella en que el complemento tiene el papel semántico de 'experimentador' y es, por tanto, 'humano' o 'animado'. Estos verbos también figuran como transitivos en los diccionarios; pero, además de que los sentidos correspondientes al esquema transitivo parecen desusados, en estos esquema es el sujeto el que recibe el papel de 'experimentador', el que ha de ser 'humano' o 'animado': Apetezco la llegada del verano (DUE); Maria repugna el olor de la gasolina (Vázquez Rozas, 1995: 187).

16 Con el sentido de «gustar o complacer extraordinariamente a alguien cierta cosa o cierta persona» (DUE). El esquema transitivo corresponde ya a otro sentido: «ejercitar sobre algo o alguien artes de magia, particularmente, convertir una cosa o persona de manera maravillosa en otra distinta» (DUE).

Aunque Cano Aguilar (1981:338) menciona desagradar como verbo que puede emplearse con objeto dirceto, con el sentido de «dar un disgusto» (A María la has desagradado) el Diccionario manual e ilustrato de la lengua española únicamente lo marca como intransitivo. El DUE, por su parte, recoge sólo este sentido: «causar la impresión correspondiente en el ánimo de alguien una cosa que sucedc y desearía que no sucediese, o algo que encuentra feo o le causa mala impresión en los sentidos», significado este que ilustra exclusivamente con esquemas transitivos: «Me desagrada mucho tener aue decir las cosas tantas veces; me desagrada el olor de la gasolina; le desagradan muchos los ruidos».

18 En gencral, como han señalado, por ejemplo, Vázquez Rozas (1995) o Hernanz y Brucart (1987), el estatus del complemento indirecto en las gramáticas del español es bastante incierto, pues 
complemento requerido por el verbo; por ello, no se ajustan al esquema de la doble transitividad que más comúnmente se ha tomado como referencia en los estudios gramaticales del español para la definición y caracterización del complemento indirecto. De ahí que, en ocasiones, no queden abarcados por la definición que se propone para el complemento indirecto, o se trate de ajustarlos al esquema de la doble transitividad mediante alguna solución más o menos ad hoc ${ }^{19}$.

Vistos los papeles semánticos y algunos de los rasgos morfosintácticos que caracterizan a los complementos - directos o indirectos- de los verbos psicológicos, una simple apreciación superficial nos llevaría a concluir, por un lado, que el complemento directo de una oración como La tardanza de María preocupó a Pedro tiene tantas, o más, semejanzas semánticas y morfosintácticas con el complemento indirecto de A María le preocupa que siempre llegue tan tarde Pedro, que con el complemento directo de Pedro barnizó la mesa o La policía registró concienzudamente el local. La mesa, el local, a diferencia de a María o a Pedro, no son un 'experimentador' humano, sino 'tema' o 'paciente'

los gramáticos rara vez coinciden en la definición y, por tanto, en el alcance de esta función. Ciertamente, hay unanimidad en la catalogación como complementos indirectos de los sintagmas introducidos por la preposición a y pronominalizables por le(s) en construcciones de doble transitividad (El portero (le) entregó las llaves al nuevo inquilino). Pero la coincidencia ya no se hace cxtensiva a los complementos no valenciales o dativos (A María se le ha casado el hijo), en tanto que el estatus de los complementos introducidos por $a$ y pronominalizables por le en esquemas no transitivos (A Federico le gusta la buena vida) queda, con frecuencia, ambiguo.

También en una perspectiva lingüistica general, el estatus del complemento indirecto como función sintáctica parece controvertido. Dik (1997: 250), por ejemplo, no lo reconoce como función sintíctica. Langacker, por citar otro ejemplo, lo menciona entre las relaciones gramaticales básicas (1991: 304), pero no lo considera una relación gramatical del mismo tipo que 'sujeto' u 'objeto directo'. Desde st punto de vista se caracterizaría de un modo más adecuado en términos de pape] semántico (1991:326).

19 La Real Academia en su Esbozo (1973) clasifica como indirectos los complementos de verbos «intransitivos» como agradar, placer, gustar, que designan «la persona, animal o cosa a quien se refiere la acción en el concepto general de daño o provecho» (1973: 375). Sin embargo, parece claro que no quedarían abarcados por la definición que ofrece de complemento indirecto: «el vocablo que expresa la persona, animal o cosa en que se cumple o termina la acción del verbo transitivo ejercida sobre el objeto directo» (1973:371).

Asimismo, la caracterización que plantea Vera Luján (1994), por ejemplo, para el complemento indirecto, no parece que convenga a este tipo de complementos, puesto que da a entender que la «categoría de función» complemento indirecto presupone la existencia de un complemento directo.

Hernanz y Brucart (1987) eluden pronunciarse sobre el estatus de los complementos pronominalizables por le con verbos como gustar y similares, aunque parecen decantarse por considierar que cl sujeto de las construcciones es nada más un sujeto superficial, nacido en una posición de 'tema', según una línea de análisis seguida en el ámbito generativista. En cualquier caso, sí destacan que los objetos subcategorizados por estos verbos no serían analizables como complementos indirectos een virtud del criterio de la doble transitividad» (1987:261), incluido en su definición de este complemento: «un argumento interno ligado a verbos que subcategorizan además un $\mathrm{Cl}) \gg(1987: 256)$. 
inanimado; pueden pasar a sujeto de una construcción pasiva (La mesa fue barnizada; el local fue registrado concienzudamente por la policía); no van precedidos de preposición y únicamente pueden ser integrados en el predicado por el clítico de acusativo en caso de supresión o de tematización (La mesa la barnizó Pedro; el local lo registró la policía).

En apoyo de la semejanza entre estos complementos (directos e indirectos) podríamos aducir que, por ejemplo, la definición de CI que se incluye a continuación podría aplicarse tanto al complemento a María como a Pedro en nuestros ejcmplos, a excepción de la puntualización sobre el género del antecedente y sin entrar a discutir la posible reflexivización de los complementos ${ }^{20}$ :

Scrá complemento indirecto aquel argumento subcategorizado por el verbo, precedido de la preposición A, pronominalizable por $L E(S)$ (siempre que sc trate de la tercera persona, sin importar el género del antecedente), que no pasa a sujeto de una oración pasiva y que no puede tomar la forma reflexiva (Sánchez Lancis, 1988: 77).

Por otro lado, la única diferencia formal apreciable entre ambos parece radicar en cl uso del clítico; un uso fluctuante, además, con los verbos del primer tipo y en el que, en cualquier caso, también hay que considerar la incidencia del leísmo.

Puede parecer, es cierto, que resulta algo superficial reducir al clítico el cambio de un complemento directo a uno indirecto, pero, evidentemente, nos veríamos abocados a ello de ceñinos a la sustitución pronominal como criterio para identificar —o incluso para definir- los complementos.

\section{En torno a dos concepciones de las funciones sintácticas}

Aunque no es infrecuente que los rasgos morfosintácticos en sí se hayan presentado como atributos que sirven para definir los complementos ${ }^{21}$, o, más

20. La aplicación de la posibilidad de reflexivización (véase Sánchez Lancis, 1988; Monzón, 1984) para diferenciar dativos y complementos indirectos es, quizá, una muestra de que el deseo de wazar límites objetivos y claros para las funciones sintácticas puede llevar a una selección algo arbitraria de rasgos delimitadores. Curiosamente, Sánchez Lancis y Monzón utilizaban la reflexivización de una manera completamente opuesta. Mientras que para Sánchez Lancis son complementos indirectos los constituyentes que no pueden tomar la forma reflexiva, para Monzón es todo lo contrario: son dativos los que no se reflexivizan y complementos indirectos los que si aceptan la forma reflexiva. De todas formas, pueden ser bastante discutibles algunos de los ejemplos que utilizan. Es discutible, pongamos por caso, que Jucan se contó un chiste sea agramatical - lo es a juicio de Sánchez Lancis- aunque pueda denotar un comportamiento algo extraño por parte de Juatin.

Para Hernanz y Brucart (1987: 256), por ejemplo, el complemento indirecto se «define» como «un argumento interno ligado a verbos que subcategorizan además un $\mathrm{CD}$, introducido siempre por la preposición a (nunca por para) sustituible por la forma pronominal de dativo le(s) $\mathrm{y}$, por 
aún, que su caracterización se haya reducido únicamente a estos aspectos, parece también admitido que los rasgos morfosintácticos no definen la naturaleza de las funciones sintácticas; representan los medios a través de los cuales se identifican en una lengua, pero son secundarios con respecto a ellas ${ }^{22}$. Por el contrario, parece existir un cierto consenso, extensivo a distintas orientaciones teóricas, acerca de que las funciones sintácticas son categorías con algún tipo de importe semántico; que son, en definitiva, «moldes que dan cobertura a mensajes significativos» (Moure, 1996: 141).

Quizá en consonancia con esa perspectiva, en la lingüística funcional española de corte estructuralista las funciones sintácticas han sido conceptuadas como signos o como partes de signo (cf. Alarcos, 1977; Rojo, 1979; Gutiérrez Ordóñez, 1983; Vcra Luján, 1994); en cualquier caso, como categorías que se asocian a algún lipo de significado. No obstante, de acuerdo con la óptica discreta, omnipresente en el estructuralismo clásico — según la cual las variaciones podían relegarse al plano de lo sustancial - las aproximaciones a la naturaleza semiótica de las funciones sintácticas se han centrado, ante todo, en las invariantes del plano del significante ${ }^{23}$ o del plano del significado; esto es, en los rasgos que puedan convenir a todas y cada una de las ocurrencias de las funciones sintácticas concretas, dejando fuera la variación, los rasgos que no están presentes en todas ellas.

Esta vía ha enfatizado, desde luego, la importancia de los rasgos significantes - los constantes en todos los casos- en la identificación de las funciones ${ }^{24}$, pero no parece haber logrado una aproximación muy satisfactoria al plano del

último, capaz de ser duplicado por el citado pronombre, aun cuando no se haga efectivo el fenómeno de tematización». Recuérdese asimismo, la «definición», anteriormente citada, que proponía Sánchez Lancis para el complemento indirecto.

22 Baste recordar a este respecto que los procedimientos formales, así como los rasgos de comportamiento sintáctico, carecen de validez interlingüística; esto es 'sujeto', 'complemento directo', 'complemento indirecto', se expresan en las lenguas mediante recursos diversos, y otro tanto cabe decir del comportamiento sintáctico de estos elementos. Difícilmente, pues, podríamos encontrar en ellos los fundamentos para categorías tan generales como 'sujeto", 'complemento directo', 'complemento indirecto'. Ello no obsta, claro está, para que puedan establecerse generalizaciones sobre los procedimientos de marcación, o los rasgos de comportamiento que, como dice Langacker (1991: 305), alertan sobre el estatus especial de las funciones sintácticas centrales, frente a los elementos periféricos o circunstanciales (cf. Moreno Cabrera, 1991: 419 y sigs.; GarcíaMignel, 1995: 27 y sigs., 1995b: 41 y sigs.).

23. Para Vera Luján (1994: 86-87), por ejemplo, el significante de la «categoría de función» complemento dirccto es la relación de concordancia en género, número y persona, entre las formas pronominales átonas de acusativo y sus correspondientes formas pronominales tónicas; la forma signilicante de la «calegoría de función» complemento indirecto, sería, a su vez, la concordancia en número y persona entre el pronombre tónico y el clítico de dativo.

24 Decía Gutiérrez. Ordóñez, por ejemplo que «lo que hacemos para determinar las funciones sintácticas es buscar sus significantes» (1997: 90), incluyendo entre los significantes «casos (en las lenguas que conocen el accidente flexión casual), posición, orden, posibilidades de conmutación (por pronombres átonos - dependiendo de sus diferentes paradigmas-, por pronombres tónicos, por adverbios, ctc.; conmutación por cero)» (1997: 97). 
signilicado; en este aspecto, lo que ante todo se ha dejado claro es en qué no consiste su significado: como invariantes linguísticas de carácter abstracto, sujeto, complemento directo, complemento indirecto, no se identifican ni con papeles semánticos (agente, causa, paciente, experimentador, receptor, destinatario), ni con papeles informativos o pragmáticos (tema, rema o tópico, comentario); de ahí que funciones sintácticas, funciones semántica y funciones informativas se hayan mantenido como planos separados. Las caracterizaciones positivas, sin embargo, son bastante más elusivas, pues ciertamente resulta difícil apreciar qué tipo de importe semántico, realmente distintivo y vinculado a la presentación lingüística de los hechos, se halla asociado a los conceptos de sujeto, complemento directo, complemento indirecto. No es extraño, pues, que haya sido el 'significante' el plano privilegiado.

Por ejemplo, según los planteamientos de Gutiérrez Ordóñez, la función abstracta 'sujeto' — como invariante que se realiza en sintagmas concretos- sería «una función signo, donde 'SN concordante' sería forma de expresión y 'sujeto' lorma de contenido» (1997: 85); esto es, como destaca Vera Luján (1990: 39), 'sujeto' es propuesto a su vez como uno de los componentes del signo 'sujeto', hecho que, a su juicio, resulta poco clarificador, desde el momento en que 'sujeto', 'complemento directo', 'complemento indirecto' son denominaciones arbitrarias, aunque asentadas por la tradición, cuyo contenido es precisamente lo que se debe determinar.

Por su partc, Vera Luján (1994: 80) afirmaba que, tratándose de signos metalingüísticos, las «categorías de función» oracionales se corresponderían con significados metalingüísticos: «los distintos estadios de determinación respecto del núclco predicativo en que consiste cada categoría de función». Así la calegoría de función $\mathrm{CD}$, cuyo significante vendría dado por los mecanismos de concordancia con las formas pronominales átonas de acusativo, tendría como significado especílico «margen del núcleo oracional», del núcleo predicativo. La categoría de función complemento indirecto, tendría, a su vez, como significado metalingüístico «periferia», debido a su relativa marginalidad respecto de la relación entre el núcleo del predicado y el CD.

Las caracterizaciones propuestas se refieren a las «funciones abstractas», a las «categorías de función $n »^{25}$, pero, al fin y al cabo, la función abstracta ha sido, en el funcionalismo estructuralista, la faceta más destacada, y puede servir de referencia para valorar mínimamente una concepción de las funciones desde una óplica que hemos calificado como 'formalista' y 'discreta', pues se apoya básicamente cn aspectos formales y tiende a enfatizar los rasgos invariantes, los

25. Las variantes, en el planteamiento de Vera Luján, por ejemplo, corresponderían, no a las categorías, sino a las clases. Téngase pues en cuenta que, según señalan Cifuentes Honrubia y Llopis Ganga (1996; 61), «como A. Vera reconoce la naturaleza prototípica de los elementos lingüísticos - propuesta de la cue ha sido pionero en España- deja abierta la posibilidad de variaciones dentro de los elementos que cumplen esta función». 
rasgos que conviene a todos — pero sólo a ellos - los miembros de una categoría o clase.

Podríamos comenzar por indicar - aunque el problema no atañe tanto a la perspectiva como a su proyección en un caso particular- que ni el significado metalingüístico 'periferia' (Vera, 1994: 80), ni la menor integración -menor en relación con el CD- en el ámbito de la significación verbal (Gutiérrez Ordóñez, 1977-1978; 1997b: 146), parecen propiedades que convengan a los complementos indirectos con verbos psicológicos. Su vínculo con el núcleo predicativo parece, por el contrario, similar al que mantiene el complemento directo, como hemos comentado: ambos constituirían el único complemento seleccionado por el verbo en una predicación biactancial. Pero, al margen de ello, también se pueden señalar otros inconvenientes de esta perspectiva para dar cuenta de los CD y los CI con verbos psicológicos o, incluso, de las funciones centrales en general.

En primer lugar, si las funciones sintácticas, según señalara ya Daneš ${ }^{26}$, desempeñan un papel en la presentación lingüística de los hechos, o de los estados de cosas mediante los cuales nos referimos a las situaciones reales, tal vez habría que buscar en ello los valores -incluso los esquemáticos o invariantesde lunciones tales como 'sujeto', 'complemento directo', 'complemento indirecto'. Pero, según se señaló anteriormente, resulta difícil conectar valores metalingüísticos, inmanentes, internos, del tipo «forma de contenido 'sujeto'», «margen» o «periferia» del núcleo oracional con ese papel en la configuración lingüística de las situaciones.

En segundo lugar, centrar la caracterización de las funciones sintácticas en rasgos teóricamente constantes, aplicables a todos los miembros de la clase, con valores significativos tan abstractos que resultan inaplicables, apoyados en uno o más rasgos significantes, puede resultar simple, económico y difícilmente relutable, pero también puede ser, además de excesivamente simplificador, poco revelador como caracterizador de la clase. Con palabras de Langacker (1987: 16), releridas a la categorización discreta en general,

A set of properties sufficient to pick out all and only the members of a class might still be incomplete and inadequate as a characterization of that class. Thus, if the semantic specifications [FEATHERLESS] and [BIPED] were in fact adequate as criterial features for defining the class of humans, we

26 Decía al respecto que, por ejemplo, John likes music y Music pleases John pueden ser cognilivanente iguales, pero la presentación lingüística de los hechos es diferente, y de ello es únicamente responsable la cstructura gramatical, las funciones sintácticas que asumen los componentes oracionales. En el primer caso, John, el sujeto, es presentado como el portador de la actitud que tiene por objeto a music; en el segundo, music, en tanto que sujeto, se presenta como la causa u origen del placer de $J o h n$ y este como el receptor, el afectado por el proceso (Daneš, 1968: 61). 
would nevetherless hesitate to accept that these two features as a comprehensive or revealing description of our species.

Así, por ejemplo, es evidente que la integración mediante el clítico de acusativo es, desde luego, un rasgo de aplicación más general a los complementos directos que la conversión en sujeto de una construcción pasiva, o el papel de 'paciente' afectado por la acción de un 'agente' que, evidentemente, no es algo que se ajuste a todos los complementos directos. Igualmente, el rasgo 'humano', además de ser - como 'experimentador'- de carácter semántico, parece menos general en los complementos indirectos que la sustitución por el clítico de dativo. Pero hacer hincapić únicamente en la posibilidad de sustitución por los clíticos, además de que, según señala Rojo (1994: 19) ${ }^{27}$ puede ser teóricamente incorrecto, obstaculizaría la vía para explicar muchos otros aspectos que atañen a los complementos: por qué se pasiviza o no se pasiviza una construcción con complemento directo; por qué los predicados con un sujeto 'causa' y un 'experimentador' como complemento directo no admiten la conversión pasiva y sí la aceptan, en cambio, los predicados con un sujeto 'experimentador' y un 'tema' u 'objeto' como complemento (Los tiranos son temidos por todo el mundo); por qué con ciertos verbos de desplazamiento cuando la ubicación es una entidad humana se utiliza, en lugar del locativo, el complemento indirecto (Le puse una gorra al niño; le tiré un pedrusco a Pedro) (cf. Cifuentes Honrubia y Llopis Ganga, 1996). Asimismo, el recurso al clítico puede llevar a concluir, de manera automálica, que el complemento de A maría sí consiguió emocionarla el abuelo pertenece a la clase de los directos, en tanto que el de A María le emociona el hecho de que te hayas acordado se incluiría en la clase de los indirectos; pero, desde luego, esto no nos diría mucho sobre las diferencias de significado entre las construcciones con $\mathrm{CD}$ y con $\mathrm{CI}$, ni nos explicaría, por ejemplo, por qué las vacilaciones en el uso del clítico (A María la/le emociona la ópera) se dan especialmente con estos complementos. La única conclusión, un tanto circular, a que nos Ilevaría el énfasis en el clítico, como rasgo suficiente y necesario para incluir en una clase un complemento, es que emocionar puede llevar CD o CI, pucsto que puede integrar su complemento por $l o / l a(\mathrm{CD})$ o por $l e(\mathrm{CI})$.

Pero aunque el clítico pueda ser una marca indicativa de un cambio, no puede considerarse la razón ni la explicación última del cambio operado. Si su uso, como ya se ha comentado, viene motivado por la interacción de factores informativos y semánticos — papel semántico del sujeto, aspecto, tematización

27 A juicio de Rojo (1994: 19-20), el procedimiento de la sustitución pronominal es demasiado rígido y «ademús de todo lo que se puede decir acerca de la evolución del sistema pronominal y de los difcrentes sistemas que conviven en la actualidad, este modo de proceder supone la inversión del procedimiento teóricamente esperable, ya que en lugar de proporcionar el modo de identificar mediante rasgos formales una unidad abstracta (la función) termina remitiendo a una única entidad absiacta todo açuello que presenta la misma apariencia superficial o puede comportarse del mismo modos. 
del complemento- que varían independientemente y afectan a otros componentes de la relación predicativa, debe radicar en ellos, en última instancia, la razón del cambio gradual de esquema sintáctico.

De las investigaciones que se inscriben en la órbita del paradigma funcionalista —en la que, siguiendo a Rojo (1994), incluimos la Gramática cognitiva - se desprende, desde luego, una vía de aproximación a las características de las funciones sintácticas algo distinta.

En primer lugar, parece claro que, en los planteamientos de Dik o Langacker, pongamos por caso, las funciones se perfilan, en primera instancia, como categorías con un importe nocional o semántico: codifican la perspectiva, el punto de vista, el enfoque de la escena y la prominencia o centralidad relativa de los participantes en la relación predicativa ${ }^{28}$. Ese planteamiento a su vez implica tomar en consideración los factores que pueden incidir en la selección de la perspectiva, el punto de vista o la mayor o menor prominencia relativa de los elementos participantes en la situación descrita. De ahí que, si bien en la Gramática funcional o en la Gramática cognitiva las relaciones gramaticales o funciones sintácticas, los papeles semánticos y las funciones informativas o pragmáticas se mantienen como categorías separadas, sí se establecen entre ellas correlaciones significativas, a través, fundamentalmente, de los distintos tipos de 'jerarquías' — de 'papeles semánticos', de 'determinación', de 'animación', de 'empatía', de 'topicalidad'- aplicadas en los estudios de orientación tipologista ${ }^{29}$.

'Agente', 'tema' o 'tópico dado' y 'sujeto', no se identifican, pues no siempre coinciden en la misma unidad las tres categorías; como tampoco se identifican 'objeto', 'paciente' y 'tópico nuevo', pongamos por caso. Pero si los

28 Con palabras de Dik (1997: 64), «Subject and Object function are used in FG tu capture de different 'points of view' from which the SoA coded in a given predication can be presented. Formally, such different perspectives are coded through differential assignment of Subject and Object function to the terms of a predication».

Para Langacker, las funciones sintácticas básicas o centrales, codifican las entidades que se sitúan en un primer plano en la presentación lingüística de los hechos, les dan una especial prominencia, sea cual sea su papel semántico, en tanto que los elementos codificados mediante funciones no centrales quedan relegados a un plano periférico o secundario. Según sus palabras, «Choosing a participant to be the subject or object is very much akin to focusing a spotlight on it; by making these selections, the speakers directs their attention to the focused participants (as well as to the interconnections that involve them directly and thereby imposes a particular image on it» (1991: 301). 'Sujeto' y 'objeto' serían, pues, las funciones gramaticales que codifican los participantes focales, los seleccionados como centrales, «in the more abstract sense of being the most important or prominent participants» (ibid.). A su vez, también la prominencia determina una relación asimétrica entre ambos elementos focales: «we can describe the subject as the most prominent clausal participant and the object as the second most prominent participant» (1991: 321 ).

29) Como señala García-Miguel (1995: 44), «Las jerarquías permiten plantear, al menos como hipótesis, cierta correlación entre funciones semánticas, funciones informativas y rasgos inherentes de los participantes que pueden estar en la base de la asignación de las funciones sintácticas centrales». 
'agentes', o las entidades 'humanas' 'definidas', tienden a seleccionarse como 'tópico' y como participante más prominente en una relación predicativa, es lógico que con frecuencia coincidan, y así suele señalarse en las descripciones lingüísticas, se incluyan o no en la órbita funcionalista.

En segundo lugar, aunque el esquema invariante, compatible con todos los miembros de una clase pueda considerarse necesario como límite categorial (cf. Langacker, 1987: 371), los trabajos que se inscriben en la órbita funcionalista han venido a enfatizar la importancia de los prototipos, compuestos por múltiples propiedades, en la explicación del funcionamiento gramatical, además de, claro está, su pertinencia cognitiva o conceptual. Así es innegable el relieve que alcanza el prototipo de la transitividad, base, a su vez, de los prototipos correspondientes al sujeto y al complemento directo, las dos categorías gramaticales básicas en la cláusula biactancial, sobre la que se perfila la relación de transitividad.

Del concepto de prototipo, tal como se ha aplicado a la transitividad o a esas dos relaciones básicas - aplicación que responde, fundamentalmente, a la denominada 'teoría estándar ${ }^{3(1)}$ — se podrían destacar las siguientes propiedades:

A diferencia del esquema o la invariante, el prototipo no se ciñe a una descripción minimalista, sino que se caracteriza por múltiples propiedades. Con palabras de Langacker (1987: 17), el modelo prototípico «encourages the fullest possible characterization of prototypical instances, if only to specify the basis for assimilating the full range of nonprototypical instances to the category».

Así, la 'transitividad prototípica', según el modelo establecido por Hopper y Thompson (1980) no se caracteriza, evidentemente, por la presencia de un sujeto y un objeto, sino por diferentes factores en los que tienen cabida el papel semántico del sujeto y del objeto, los rasgos semánticos (humano, inanimado, definido, indefinido) inherentes a ellos, la clase semántica del verbo (acción, estado, proceso), la modalidad y el aspecto (perfectivo, imperfectivo, télico, atélico).

Federico barnizó las sillas; la policía registró el local, por ejemplo, representan una relación transitiva prototípica, en cuanto que el sujeto es 'agente', 'humano', 'definido' y realiza de manera deliberada y voluntaria la acción; el predicado es, por tanto, de 'acción' (no de 'estado' o 'proceso'); el paciente es 'inanimado', 'referencial' — representa una entidad preexistente y separada de la

31 Según señala Kleiber (1995), en la teoría del prototipo se pueden diferenciar al menos dos momentos: la teoría estándar, basada en el ejemplar idóneo o entidad compuesta por atributos típicos, y la teoría ampliada, sustentada en el 'parecido de familia'. De conformidad con el mismo Kleiber, la teoría estándar no sólo no ha muerto, sino que sigue siendo la más conocida y, también, la más utilizada. Quizá sea porque la teoría ampliada no parece dar una respuesta adecuada a una cuestión clave en un modelo de categorización, como es el dar cuenta de la pertenencia de una una unidad a una categoría. Con palabras de Kleiber (1995: 144), «al rechazar el prototipo como entidad organizadora se le está privando también de todo poder para explicar la pertenencia de una entidad a una categorías. 
acción verbal - y totalmente afectado por la acción descrita por el verbo; es, asimismo, una acción 'télica' por lo que concierne al aspecto. Pero, según este modelo, Los truenos asustan a los niños; el recuerdo de las pasadas heladas atemorizaba a los agricultores, aún respondiendo a una estructura con sujeto y objeto, se alejan del prototipo en cuanto que no coinciden en esos aspectos.

Del mismo modo, aunque no todos los sujetos, como ya se ha dicho, sean 'humanos', 'agentes' o 'tópicos', ni todos los objetos 'pacientes' 'inanimados', en el prototipo del sujeto o del objeto sí está contemplado este tipo de rasgos. Desde el punto de vista de Langacker, por ejemplo (1991: 322), «whereas a subject is a prototypically an agent, human, definite, and the primary figura, an object is a patient, a physical object, specific indefinite, and the secondary figure». Similar es también la caracterización del protolipo de sujeto y de objeto que recoge, por cjemplo, García-Miguel (1995: 46): «El SUJ suele ser Agente humano, tema no marcado y definido, mientras que el CDIR suele ser Paciente, afectado físicamente por el proceso, formar parte del Rema y realizarse frecuentemente en frases nominales indefinidas».

Federico, la policía, en los ejemplos anteriores, son, pues, sujetos prototípicos; el local, la mesa, se hallan también próximos a las características propuestas para el objeto prototípico: son objetos físicos, pacientes, afectados por la acción y forman parte del rema, aunque no son sintagmas indefinidos ${ }^{31}$.

En cambio, ni el sujeto ni el objeto de La llegada de la Navidad entristece a los ancianos o la falta de noticias sobre su paradero intranquiliza a la familia coinciden en su papel semántico o en sus rasgos inherentes con los que caracterizan al prototipo de sujeto y de objeto.

En segundo lugar, aunque, evidentemente, los rasgos que se asocian al prototipo no son compartidos por la totalidad de los elementos que puedan incluirse en la categoría, el prototipo ocupa una posición central o focal en la misma, por varias razones que remiten, en última instancia a su pertiencia cognitiva en los procesos de categorización.

El prototipo es el ejemplar idóneo de la categoría, su realización no marcada en términos de frecuencia y prominencia cultural y cognitiva ${ }^{32}$; actúa de pauta o modelo para la codificación de otros elementos, próximos al prototipo aunque no

31 Es de destacar, no obstante, que el carácter 'definido' o 'indefinido' es uno de los rasgos más fluctuantes en las caracterizaciones que se plantean para el objeto prototípico.

32 Para Givón (1995: 45), «the unmarked status of active clause has his roots in a number of cognitive and cultural domains. The prototypical semantically-transitive unit has a salient agent/causc, a salient patient/effect, and a bounded realis, perfective, fast-changing verb (Hopper and Thompson, 1980). Prototypical semantically transitive events are thus perceptually more salient. The protypical pragmatically-transitive active voice in connected discourse, with the agent occupying the subject/topic grammatical role, reflects the anthropocentric orientation of human culture and human discourse». 
idénticos ${ }^{33}$; sirve de referencia para determinar, según su mayor o menor proximidad al modelo, la inclusión en una clase o categoría de un esquema o un elemento; es, asimismo, el fundamento para explicar, a través del concepto de marcación, la no homogeneidad, en cuanto a sus rasgos morfosintácticos o su comportamiento gramatical, de los elemento: que, no obstante su diversidad, se incluyen en la misma clase o categoría.

En relación con este último aspecto, cabe considerar que, en efecto, la reconocida falta de homogeneidad de los complementos directos en español no puede explicarse tomando únicamente como base el esquema abstracto, la invariante, que, teóricamente, les subyace. Por el contrario, no pasa desapercibido que esas tres «notas fundamentales» que, según destacan por ejemplo Hernanz y Brucart (1987: 251) permiten caracterizar el complemento directo (es «un SN (...) adopta la forma del clítico de acusativo cuando se pronominaliza y puede pasar a sujeto de una oración pasiva» (ibid.)) se aplican, fundamentalmente, a los complementos directos prototípicos incluidos en una relación transitiva canónica - prototípica. Es el caso, como ya comentamos, de La policía registró concienzudamente el local o Federico barnizó la silla.

Pero, en primer lugar, la viabilidad de la pasiva está claramente relacionada con las variaciones que puedan producirse en los aspectos que configuran esa transitividad prototípica. Así, no sólo se ha vinculado, por ejemplo, a la clase semántica (acción, estado, proceso) del predicado ${ }^{34}$ y al papel semántico del sujeto $^{35}$ o su mayor o menor proximidad al prototipo del sujeto, sino también al carácter más o menos referencial o individuado del objeto, a su grado de afectación ${ }^{36} \mathrm{y}$, naturalmente, al aspecto (cf. De Miguel, 1992). Juan barniza sillas; la policía registra locales regularmente denotan actividades, situaciones atélicas, con un objeto (sillas, locales) no referencial, no individuado ni

33 Así, por ejemplo, para Langacker (1991: 303-304) una cláusula transitiva como I (see/wan/love/fear/understand] it «represents an extension from the transitive-clause protype, since there is no transmission of energy from the subject to the object, which is totally unaffected by the relationship (i.e. the object's semantic role is zero). The extension is presumably grounded melaphoricallyy, either through specific metaphors such a SEEING IS TOUCHING, or more gencrally, through the shared path-like nature attributed to such phenomena as energy flow, gaze and directed attention».

34 Según señala Gràcia i Solé (1989: 220), por lo que respecta a la pasiva perifrástica «es pot observar que hi ha una gradació d'acceptabilitat (...) mentre que els verbs d'acció solen acceptar-la, els 'estatius' purs (...) no l'accepten mai; els verbs de percepció i de sentiment -en què es pot considerar un cert 'pas abstracte' d'un origen a un terme - en certes circumstàncies poden admetrela».

Parcec más viable, en electo, si el sujeto — «superficial», por supuesto, ya que no estamos considerando la posibilidad, asumida en la Teoría de la Rección y el Ligamiento de que los sujetos superficiales deriven de otra posición en una estructura más básica (véase Gràcia i Solé, 1989)— es 'agente' que si es 'causa'.

36 Gràcia i Solé (1989:237), por ejemplo, afirmaba al respecto que, aunque no es cierto que los verbos con complementos no afectados no puedan admitir la pasiva, «sí que es pot dir que en general són més normals les passives amb objectes afectacts». 
totalmente afectado, y todo ello repercute en que, a diferencia de Juan barnizó la silla; la policía registró el local, no sea factible su conversión en construcción pasiva": "Sillas son barnizadas por Juan; *locales son registrados por la policía.

En segundo lugar, también las otras dos variaciones - el leísmo, el uso de la preposición $a^{38}$ - que afectan al complemento directo en español, parecen hallarse vinculadas - siguiendo tendencias que, según ha puesto de relieve la lingüística tipológica, inciden en lenguas muy diversas- a desviaciones semánticas respecto de la transitividad prototípica y de los rasgos que, como parte del prototipo, caracterizan a los participantes centrales en la relación transitiva.

Así, la preposición a y el clítico de dativo marcan objetos que, al ser 'humanos', 'definidos' y/o 'específicos' se desvían de los rasgos semánticos inherentes del objeto prototípico, en tanto que se aproximan a los que configuran el prototipo del sujeto transitivo o a los que caracterizan al complemento indirecto -invariablemente marcado por $a$ y el clítico de dativo-, cuya coincidencia con las propiedades inherentes del sujeto prototípico ('humano', 'definido', 'específico') ${ }^{34}$ es un hecho que no ha pasado desapercibido ${ }^{40}$. No obstante, de conformidad con Pensado (1995: 37) o Delbecque (1998: 533), entre otros, las marcas del complemento no dependen únicamente de los rasgos del

37 Según de Miguel (1992: 212), «la pasiva, como la CPA [construcción de participio absoluto] expresa que un paciente ha sufrido las consecuencias del evento denotado por el predicado y requiere que el evento esté acabado o pueda acabar; pero la primera, a diferencia de la segunda, requiere además que el evento cuyas consecuencias padece el paciente haya transitado desde un agente (u otro argumento externo) a un paciente. Se explica así la necesidad de que el verbo que se pasiviza pertenezca al grupo de los transitivos (los verbos que cuentan con dos argumentos) y que denote un evento perfectivo (...) un evento que no acaba no deja sentir sus efectos o sus consecuencias sobre el paciente».

38 Aunque el leísmo tenga una menor extensión que el uso de la preposición, la conexión entre ambos fenómenos también ha sido subrayada en los estudios gramaticales del español. Desde el punto de vista de Vázquez Rozas (1995: 162), por ejemplo, es posible justificar el leísmo «en lo que se refiere a su origen y a su estado actual en ciertas zonas como un fenómeno paralelo en ciertos aspectos al empleo de la preposición a y por tanto sometido a los mismos principios generales que la aparición de $a »$. Para Pensado (1995: 14 n.), asimismo, «existe una relación clara entre el CDP [complemento directo preposicional] y el leísmo: la confusión de casos en el pronombre átono de tercera persona es, dentro de las lenguas romances, exclusivo del español, que es precisamente la lengua que teniendo marcas idénticas de CDP y Cl tiene un CDP más generalizado».

De ahí que el 'dativo'/'benefactivo' se sitúe próximo al 'agente' y, desde luego, por encima del 'paciente' en la jerarquía de la topicalidad (cf. Givón, 1995: 46), en la que está implicada el calrácter 'humano' y 'definido'.

4) Según señalaba Laca (1995: 86), «relativamente novedosa es la idea de que los objetos dativos o los dativos en general son análogos a los sujetos, sea desde el punto de vista de la postulada frecuencia real de su asociación con los rasgos definido/ humano (...) sea desde el punto de vista de una lógica actancial en la cual los dativos prototípicos se presentan como 'agentes potenciales de interacción" o bien como más cercanos al sujeto en el grado de responsabilidad que tienen en la producción del 'hecho'». 
objeto, sino tambien de otros componentes de la estructura transitiva, tales como el verbo o el sujeto ${ }^{41}$.

En definitiva, frente a las concepciones que enfatizan los rasgos invariantes como condiciones suficientes y necesarias para delimitar las funciones sintácticas, y que se apoyan, fundamentalmente, en aspectos formales, hasta el punto de identilicar - en la práctical- funciones y procedimientos de expresión o marcas, esta aproximación funcional se perfila como un enfoque de las funciones de base realmente semántica: no sólo son semánticos los valores abstractos —esquemáticos o invariantes- que pueden asociarse a las funciones sintácticas, y a ellos se subordinan los rasgos formales que «están para» diferenciarlas ${ }^{42}$, sino que también las variaciones morfosintácticas se consideran semánticamente motivadas. Se subraya, asimismo, su condición de entidades lingüísticas de carácter netamente rclacional, pues si ya son de índole relacional los conceptos (perspectiva, prominencia, etc.) utilizados para determinar su valor abstracto o genera ${ }^{43}$, la consideración de las repercusiones que pueden tener en ellas las múltiples categorías integradas en la noción de transitividad viene a poner de relieve la interrelación de los componentes de la cláusula. Con palabras de García Miguel (1995: 56), «un constituyente puede variar en su forma de expresión no sólo atendiendo a sus propias características semánticas o a la relación que mantiene con los demás, sino también reflcjando particularidades semánticas de algún otro constituyente de la estructura en que se integra».

Por último, al incorporar el concepto de prototipo en el tratamiento de las relaciones gramaticales o sintácticas, esta perspectiva funcional, frente a las aproximaciones basadas en el modelo de condiciones suficientes y necesarias ${ }^{44}$, no sólo hace aparecer — como ya se dijo— un conjunto mucho más grande de propiedades en conexión con los fenómenos vinculados a las funciones sintácticas, sino que también proyecta, como es lógico, esa imagen de las categorías como entidades heterogéneas, graduales, sin una línea de demarcación

A Así, según Pensado (1995: 37), por ejemplo, se usaría el CDP «cuando un complemento se diferencia demasiado poco del sujeto de la oración», lo cual depende en parte de la determinación y la animación, «pero también de la relación con el verbo».

42 Como destaca García-Miguel (1995b: 48), en consonancia con esta perspectiva, se debe tener en cuenta que «los procedimientos de expresión son secundarios con respecto a las funciones y que lo que cuenta en última instancia es que una función no se confunda con otra posible».

43 Al fin y al cabo, según subraya García-Miguel (1995: 59), «el valor semántico de cada función central se detcrmina por contraste con las otras funciones centrales».

4 «Condiciones necesarias» porque un elemento debe presentar las propiedades seleccionadas para scr reconocido como miembro de la categorías. «Condiciones suficientes» porque su validez viene diclada por oposición a los criterios definidores de otras categorías. Este modelo de categorización, según Langacker (1987: 16), requiere, en su forma estricta, «that every member of the class fully possess every property of the list, and that nonmember possess all of the listed properties. Class membership is thus an all-o-nothing affair; a sharp distintion is presumed between those cntitics that are in the class and those that are nots. 
rígida, que caracteriza a la perspectiva «no discreta» de la categorización lingüística.

Esto es, queda asumido, no ya como normal - y no como un defecto de la teoría-, sino incluso como una herramienta descriptiva más adecuada a la complejidad de las categorías, que los miembros de una categoría linguiística - el complemento directo, pongamos por caso- ni tienen necesariamente los mismos rasgos, ni gozan del mismo estatus, ni la condición de miembro de una categoría es cuestión de sí o no, sino también cuestión de grado. Las categorías (cf. Langacker, 1987: 17) se organizan en torno a los ejemplares prototípicos y los elementos que no responden plenamente al prototipo se asimilan a la categoría en la medida en que se aproximen a él en sus características. En consecuencia, las categorías pueden presentar una estructura gradual que va, desde los ejemplares que ocupan la posición central, hasta los elementos periféricos o limítrofes con otras categorías (cl. Moure, 1996: 63): aquellos que, por compartir pocos rasgos con el prototipo y/o por presentar características asociadas a otras categorías, se encuentran ya muy alejados del núcleo o se puede poner en duda, incluso, su pertenencia a la categoría. Así pues, tampoco sus límites están fijados mediante cortes abruptos o de un modo rígido y claro, ni los solapamientos están totalmente descartados.

\section{Los verbos psicológicos y la perspectiva funcional de base prototípica}

Aún son, sin duda, muchos los problemas ${ }^{45}$ que deben ser solventados en el tratamiento de las funciones —o de cualquier categoría lingüística- partiendo de una óptica no discreta de la categorización, de base prototípica ${ }^{46}$.

No es, sin embargo, casual que, como afirman Kleiber (1995: 99) o Moure (1996: 72), el sector de las funciones sintácticas haya sido uno de los motores de la orientación no discreta ${ }^{47}$, pues, en palabras del propio Kleiber «toda descripción muestra que existen casos indiscutibles y casos marginales» (ibid.).

En concreto, si consideramos las peculiaridades de los verbos psicológicos con un 'experimentador' como complemento, quizá debamos admitir que una caracterización de las funciones complemento directo y complemento indirecto en términos 'discretos', que, obviando otros aspectos, se apoye en las marcas significantes y en rasgos teóricamente invariantes con el objeto de fijar límites claros, sin solapamientos, y justificar la igualdad de estatus de sus miembros,

45 Entre ellos, los que atañen al concepto mismo de prototipo y a su formalización (cl. Kleiber, 1995).

to Parece claro, además, que como apuntaba Langacker (1987: 14), «discrete entities are easier to manipulate, require simpler descriptive tools, tend themselves to stronger claims, and yield theoretically more pleasing analyses».

47 Según afirmaba MacLaury (1991: 69), «[Syntactians] began to use the concept of a prototype prior to the advent of cognitive linguisties and, apparently, before some of them recognized Rosch's work». 
puede resultar escasamente reveladora, habida cuenta de la complejidad de los hechos: los rasgos morfosintácticos de los complementos directos varían en rclación con aspectos semánticos en los que están implicados otros componentes de la cláusula y son, en buena medida, esos aspectos los responsables del carácter alípico o desviado de los complementos directos que acompañan a estos verbos; las marcas - cl clítico en este caso- fluctúan en función del papel semántico del sujeto, del aspecto o de la tematización del complemento; existe solapamiento de rasgos entre complementos directos e indirectos, y faltan en ocasiones indicios claros que permitan dilucidar la categoría del complemento; con estos predicados, en definiliva, como señala Delbecque (1998: $530 \mathrm{n}$.) «la frontera entre sintaxis transitiva $c$ intransitiva», en lugar de poseer límites claros, en realidad «se difumina».

Parece razonable admitir, por el contrario, que todos estos hechos tal vez quedarían mejor reflejados partiendo de una caracterización funcional de base protolípica, que no sólo pone en juego, a través del concepto de prototipo, los aspectos scmánticos incidentes en los rasgos morfosintácticos de los objetos, sino que también da cabida a la posibilidad de solapamientos y de categorías sin un perfïl 'discreto', cuyos miembros, aun coincidiendo en ciertos aspectos, ni tienen cl mismo estatus ni son del todo homogéneos.

Cicrtamente, las construcciones que incluimos a continuación - representativas de las que hemos venido comentando- presentan indudables semejanzas en un nivel abstracto: Juan barnizó las sillas; el casero asustó a María para que se marchara; Juan tranquilizó al vecino; a María le gusta la soledad; a Federico le gusta la buena vida.

En primer lugar, son cláusulas biactanciales, con los dos participantes que cxigc una relación transitiva; incluso se puede considerar subyacente a ellas esa hipotética trayectoria, inherente a la cadena de causación (cf. Langacker, 1991: 327) que enlazal un «dominio de origen» (el correspondiente al agente o la causa) con un término o «dominio de llegada».

En segundo lugar, el complemento directo y el complemento indirecto -en gencral - lambién parecen tener algunas analogías básicas. De conformidad con García Miguel (1995: 33 y sigs.) y Vázquez Rozas (1995: 68 y sigs.), por lo que concierne a su importe semántico en la codificación lingüística de las situaciones, ambos coincidirian en presentar las entidades a las que aluden como participantes centrales en la relación predicativa ${ }^{48}$. Podríamos añadir, asimismo, tomando como base a Langacker (1991: 327) que el complemento directo y el indirecto también parecen coincidir en situar a las entidades que designan en un «dominio de

4h Según Vázquez Rozas (1995: 125-126), por ejemplo, la diferencia entre Juan se opuso a ellas --con suplemento- y Juan se les opuso - con complemento indirecto- radica en que la consirucción con el clítico de dativo «lleva consigo el contenido lingüístico propio de la función CIND que hace que la entidad en cuestión se conciba como un participante central en el proceso descrito por la cláusula». 
llegada», en esa trayectoria abstracta subyacente al esquema semántico de la cláusula. Ambos aspectos serían, pues, comunes a los complementos de las cláusulas anteriormente citadas.

Pero el complemento directo y el complemento indirecto —además, claro está, de las diferencias que existen entre ellos en lo que atañe a sus rasgos morfosintácticos - difieren en sus respectivos prototipos semánticos, según puede apreciarse en las construcciones de doble transitividad donde parece reflejarse al máximo el contraste entre ambos ${ }^{49}:$ El casero le entregó las llaves al nuevo inquilino; Juan le prestó el coche a Federico.

El complemento directo prototípico es, como ya se ha comentado, un 'paciente' 'inanimado' (las llaves, el coche) y, por tanto, potencialmente inactivo. Por el contrario, parece unánimemente aceptado que el ser 'humano', 'definido' y/o 'específico' y, por consiguiente, potencialmente activo, son rasgos que forman parte del complemento indirecto prototípico (al nuevo inquilino, a Federico), aunque ya no existe coincidencia sobre su papel semántico ni sobre otros rasgos teóricamente constitutivos del prototipo ${ }^{50}$. De hecho, ese carácter 'humano' del CI se halla indisolublemente asociado a la mayoría de los valores semánticos que se le han asignado: afección, interés, mayor grado de actividad en relación con el CD (cf. Vázquez Rozas, 1995: 75 y sigs.).

Es también en el plano de la mayor o menor proximidad a los prototipos - de la transitividad, de los complementos - donde empiezan a establecerse dilerencias entre los enunciados que hemos utilizado como ejemplos; diferencias que permiten establecer una gradación de transitividad entre ellos.

En un extremo, Juan barnizó las sillas representa, como ya destacamos en otro momento, una relación transitiva prototípica, cuyos participantes centrales se ajustan, naturalmente, a los prototipos de sujeto y de objeto: el sujeto es 'agente' 'humano', que actúa de un modo deliberado y voluntario; es, asimismo, 'definido' $y$, desde el punto de vista informativo, 'tema' no marcado; el objeto es 'paciente' 'inanimado', inactivo, forma parte del 'rema' y resulta totalmente afectado por la acción; el aspecto es perfectivo y el predicado representa una acción télica, una acción que alcanza su término.

En el otro extremo, se situarían las construcciones con complemento indirecto, tanto aquellas en las que el verbo psicológico no admite otro complemento (A Federico le gusta la buena vida), como aquellas cuyo verbo puede ser utilizado, en otros casos, con complemento directo (A María le asusta la soledad). A estas, aunque son cláusulas biactanciales, con dos participantes

44) Véanse, por ejemplo, los datos que aporta García-Miguel (1995: 51 ).

5) Según scñala Langacker (1991: 327-328) 'receptor' y 'experimentador' son los dos candidatos a papeles prototípicos del complemento indirecto. A su juicio, es difícil argumentar sobre cuál de los dos es más básico, porque están muy asociados y es difícil distinguirlos. No obstante, parece decantarse por el papel de 'experimentador', de ahí que caracterice al CI como «an active experiencer in the target domain». 
centrales y el complemento sitúa al 'experimentador' en el «dominio de llegada», les corresponde otra pauta semántica, por cuanto parecen subvertir los rasgos que configuran el prototipo de la transitividad básica: el sujeto forma parte del rema, y no es 'agente' 'humano' sino 'causa' 'inanimada'; el complemento es 'humano', 'definido' y 'específico', potencialmente más activo que el sujeto, y aparece como 'tema' en la estructura informativa de la cláusula ${ }^{51}$; el aspecto es imperfectivo y el predicado designa un estado, una situación atélica, no dinámica y no controlada.

Así pues, cabe admitir que, como afirma Vázquez Rozas (1995: 173), estas construcciones biactanciales con complemento indirecto marcan una estructura semántica desviada, con respecto a la estructura transitiva prototípica, la no marcada. O, de otra manera, la construcción biactancial con complemento indirecto parece formar parte de las estrategias de que disponen las lenguas «para codificar cláusulas muy bajas en transitividad como intransitivas aunque posean dos participantes» (Moure, 1996: 161).

Entre las construcciones transitivas prototípicas, con un complemento directo canónico en cuanto a sus rasgos morfosintácticos y las construcciones con complemento indirecto en que se subvierten complementamente los rasgos, podrían situarse, pero en distintas posiciones, el resto de los enunciados que hemos planteado.

En El casero asustó a María para que se marchara; Juan tranquilizó al vecino, el complemento no es, por lo que concierne a sus rasgos semánticos, un complemento directo prototípico. Antes bien, como ya se ha mencionado, al ser 'humano' y 'definido' se aproxima al prototipo del $\mathrm{CI}$; de ahí su carácter marcado, que determina el uso de la preposición y la posible incidencia del lcísmo. Pero, evidentemente, la construcción, como un todo, se aproxima al protolipo transitivo: el sujeto es 'agente' 'humano' y actúa de un modo voluntario; es 'definido' y 'tema' no marcado desde el punto de vista informativo; el aspecto es perfectivo y el predicado designa un proceso delimitado, un proceso con su término. El complemento es, en consecuencia, aunque no prototípico, un complemento directo claro.

La llegada de la Navidad entristece a los ancianos se desvía en mayor medida del prototipo, en tanto que se aproxima a la pauta expresada en el esquema intransitivo: el sujeto no es 'agente' 'humano', ni el aspecto es perfectivo, ni cl predicado designa un proceso delimitado. El complemento, al ser un 'experimentador' 'humano' es potencialmente más activo que el sujeto. Eso sí, el sujeto sigue siendo el 'tema' no marcado desde el punto de vista informativo. Se podría considerar, pues, una construcción limítrofe y/o periférica en relación con el csquema transitivo y, de hecho, el complemento no presenta rasgos claros

51 Cabe destacar que, en función de su carácter 'humano' y 'definido' ocuparía un lugar más alto que cl sujeto en la jerarquía de la topicalidad, en la que, como ya se señalo, están contemplados estos aspectos. 
que permitan considerarlo, de un modo tajante, como un complemento indirecto en una cláusula biactancial o como un complemento directo desviado.

En esta gradación que hemos presentado, las cosas, evidentemente, se han simplilicado. Está claro, por ejemplo, que son posibles muchas más variaciones combinando la tematización, el aspecto, la voluntariedad, el control y el carácter 'humano' o 'inanimado' del sujeto. $\mathrm{Y}$, seguramente, habremos pasado por alto muchos otros aspectos que, quizá, deberíamos haber considerado. Pero tal vez haya servido, al menos, para ilustrar algunas de las cuestiones relativas al tratamiento de las funciones sintácticas que hemos venido enfatizando. Entre ellas: que los elementos que pueden incluirse en una categoría sintáctica -como el complemento directo, pongamos por caso-, aunque son similares en varios aspectos, pueden diferir en sus rasgos morfosintácticos, y sus diferencias pueden venir motivadas tanto por rasgos semánticos propios como por aspectos scmánticos en cuya configuración intervienen otros componentes de la cláusula; que la incorporación del concepto de prototipo, al proyectar en las descripciones sintácticas un amplio conjunto de propiedades informativas y semánticas, parece una herramienta adecuada para dar cuenta de la heterogeneidad de los elementos incluidos en las categorías sintácticas; que, asimismo, la consideración del prototipo como pauta para determinar la condición de miembro de las categorías, permitiendo distinguir, por tanto, ejemplares protípicos o nucleares y ejemplares periléricos o desviados, posibilita explicar, de manera natural, que existan solapamientos, o casos problemáticos, o variaciones sutiles que se reflejan en cambios de esquema sintáctico, como en el caso de los predicados que hemos venido considerando; permite explicar, en definitiva, que, como frecuentemente se ha señalado, el hecho de que un elemento se incluya o no en una categoría, no es una simple cucstión de sí o no, sino también una cuestión de grado.

\section{Referencias bibliográficas}

ALARCOS LLORACH, E. (1977): «Metodología estructural y funcional en lingüísticâ), RSEL, 7, 2, pp. 1-16.

ALARCOS LLORACH, E. (1994): Gramática de la lengua española, Madrid, Espasa Calpe.

BELLETTI, A. y L. RIZZI (1987): «Los verbos psicológicos y la teoría temática», en DEMONTE, V. y M. FERNÁNDEZ LAGUNILLA (eds.), Sintaxis de las lenguas románicas, Madrid, Ed. El Arquero, pp. 60-122.

BROWN, K. y MILLER, J. (eds.) (1996): Concise Encyclopaedia of Syntactic Theories, Oxford, Pergamon.

CANO AGUILAR, R. (1981): Estructuras sintácticas transitivas en el español actual, Madrid, Gredos. 
CIFUENTES HONRUBIA, J. L. y J. LLOPIS GANGA (1996): Complemento indirecto y complemento de lugar: Estructuras locales de base personal en español, Alicante, Universidad de Alicante.

DANE ̌́, F. (1968): «Some thoughts on the semantic structure of the sentence», Lingua, 21, pp. 55-69.

DELBECQUE, N. (1998): «La dimensión paradigmática de la alternancia $a / \varnothing$ en la construcción transitiva y más allá», en CIFUENTES HONRUBIA, J. L. (ed.), Estudios de lingiiística cognitiva, Alicante, Universidad de Alicante, pp. 527-548.

DE MIGUEL APARICIO, E. (1992): El aspecto en la sintaxis del español: Perfectividad e impersonalidad, Madrid, Ediciones de la Universidad Autónoma de Madrid.

DIK, S. C. (1997): The Theory of Functional Grammar. Part 1. The Structure of the Clause, Berlin, New York, Mouton de Gruyter, $2^{\text {a }}$ ed.

FERNÁNDEZ LAGUNILLA, M. y A. ANULA REBOLLO (1995): Sintaxis y cognición. Introducción al conocimiento, el procesamiento y los déficits sintácticos, Madrid, Síntesis.

FERNÁNDEZ ORDÓNEZZ, I. (1993): «'Leísmo, laísmo y loísmo’. Estado de la cuestión», en FERNÁNDEZ SORIANO, O. (ed.), pp. 63-96.

FERNÁNDEZ SORIANO, O. (ed.) (1993): Los pronombres átonos, Madrid, Taurus.

GARCÍA-MIGUEL, J. M. (1995): Transitividad y complementación preposicional en español, Verba, Anexo 40, Universidade de Santiago de Compostela.

GARCÍA-MIGUEL, J. M. (1995b): Las relaciones gramaticales entre predicado y participantes, Santiago de Compostela, Universidade de Santiago de Compostcla.

GIVON, T. (1995): Functionalism and Grammar, Amsterdam/Philadelphia, John Benjamins.

GÓMEZ TORREGO, L. (1993): Manual de español correcto II, Madrid, Arco Libros, $4^{\mathrm{a}} \mathrm{ed}$.

GRÀCIA I SOLÉ, LL. (1989): La teoria temàtica, Barcelona, Universitat Autónoma de Barcelona.

GUTIÉRREZ ORDÓÑEZ, S. (1977-1978): «Sobre los dativos 'superfluos'», Archivum, XVII-XXVII, pp. 415-452.

GUTIÉRREZ ORDÓÑEZ, S. (1983): «La determinación inmanente de las funciones en sintaxis», Contextos, 2, pp. 41-56.

GUTIÉRREZ ORDÓÑEZ, S. (1997): Principios de sintaxis funcional, Madrid, Arco Libros.

GUTIÉRREZ ORDÓÑEZ, S. (1997b): La oración y sus funciones, Madrid, Arco Libros.

HERNANZ, M. LL. y J. M. BRUCART (1987): La sintaxis, Barcelona, Crítica. 
HOPPER, P. J. y S. A. THOMPSON (1980): «Transitivity in Grammar and Discourse», Language, 56, 2, pp. 251-299.

KLEIBER, G., (1995): La Semántica de los prototipos. Categoría y sentido léxico, Madrid, Visor Libros.

KLIFFER, M. D. (1995): «El 'A' personal, la kinesis y la individuación», en PENSADO, C. (ed.), pp. 93-111.

LACA, B., (1995): «Sobre el uso del acusativo preposicional en español», en PENSADO, C. (ed.), pp. 61-91.

LANGACKER, R. W. (1987): Foundations of Cognitive Grammar. Vol. I. Theoretical Prerequisites, Stanford, Stanford University Press.

LANGACKER, R. W. (1991): Foundations of Cognitive Grammar. Vol. II. Descriptive Application, Stanford, Stanford University Press.

MACLAURY, R. E. (1991): «Prototypes revisited», Annual Review of Anthropology, 20, pp. 55-74.

MOLINER, M. (1970): Diccionario de uso del español, Madrid, Gredos.

MONZÓN, C. (1984): «Hacia una aclaración de la función dativo en español», RSEL, 14, 1, pp. 63-84.

MORENO CABRERA, J. C. (1991): Curso universitario de lingüística general. Tomo I: Teoría de la gramática y sintaxis general, Madrid, Síntesis.

MOURE, T. (1996): La alternativa no-discreta en lingïística. Una perspectiva histórica y metodológica, Santiago de Compostela, Universidade de Santiago de Compostela.

PENSADO, C. (ed.) (1995): El Complemento directo preposicional, Madrid, Virsor libros.

PENSADO, C. (1995): «El complemento directo preposicional. Estado de la cuestión y bibliografía comentada», en PENSADO, C. (ed.), pp. 11-59.

REAL ACADEMIA ESPAÑOLA (1973): Esbozo de una nueva gramática de la lengua española, Madrid, Espasa Calpe.

REAL ACADEMIA ESPAÑOLA (1989): Diccionario manual e ilustrado de la lengua española, Madrid, Espasa Calpe, $4^{\mathrm{a}} \mathrm{ed}$.

ROJO, G. (1979): «La función sintáctica como forma del significante», Verba, 6, pp. 107-151.

ROJO, G. (1983): Aspectos básicos de sintaxis funcional, Málaga, Ágora.

ROJO, G. (1994): «Estado actual y perspectivas de los estudios gramaticales de orientación funcionalista aplicados al español», Verba, 21, pp. 7-23.

SÁNCHEZ LANCIS, C. E. (1988): «Hacia una nueva definición del complemento indirecto en español», Estudi General, 8, pp. 65-79.

VÁZQUEZ ROZAS, V. (1995): El complemento indirecto en español, Santiago de Compostela, Universidade de Santiago de Compostela.

VERA LUJÁN, A. (1990): Las construcciones pronominales impersonales y pasivas en español, Murcia, Universidad de Murcia. 
VERA LUJÁN, A. (1994): Fundamentos de análisis sintáctico, Murcia, Universidad de Murcia.

WILLEMS, D. y L. MELIS (1997): «Introduction», en WILLEMS, D. y L. MELIS (eds.), Les objets: relations grammaticales et rôles sémantiques, Travaux de Linguistique, $\mathrm{n}^{\circ} 35$, pp. 5-10. 